\title{
GÊNERO E ACESSO AO CRÉDITO RURAL NA ASSOCIAÇÃO MUNICIPAL MULHER FLOR DO CAMPO EM PERNAMBUCO
}

\author{
Gerlúcio Moura Bezerra de Sousa \\ Maria das Graças Andrade Ataíde de Almeida ${ }^{2}$ \\ Maria do Rosário de Fátima Andrade Leitão ${ }^{3}$
}

\begin{abstract}
RESUMO
O artigo analisa o acesso ao crédito rural, por mulheres vinculadas à Associação Municipal de Desenvolvimento Produtivo das Mulheres Trabalhadoras Rurais e Artesãs Rurais de Santa Cruz da Baixa Verde-PE. A inclusão destas mulheres no Programa Nacional de Fortalecimento da Agricultura Familiar - Pronaf, foi analisado a partir das categorias teóricas relações de gênero e divisão sexual do trabalho. Trata-se de uma pesquisa qualitativa, na qual a entrevista semiestruturada constituiu-se em principal instrumento de coleta de dados. A análise foi fundamentada em pressupostos teóricos metodológicos da Análise do Discurso (AD) elaboradas por Foucault e Dijk. Os resultados evidenciaram que, apesar dos avanços no que se refere ao acesso destas mulheres ao crédito do Pronaf, ele é operacionalizado, a partir do diálogo e das contribuições realizadas pelos respectivos companheiros. Desse modo, mantêm-se a hierarquização de poder no processo de gerenciamento destes recursos econômicos, mas elas galgaram espaços culturais, políticos e de tomada de decisão.
\end{abstract}

Palavras-chave: análise de discurso, mulheres rurais, Pronaf.

\section{GENDER AND ACCESS TO RURAL CREDIT IN THE ASSOCIAÇÃO MUNICIPAL MULHER FLOR DO CAMPO IN PERNAMBUCO}

\begin{abstract}
The article analyzes the access to rural credit by women linked to the Associação Municipal de Desenvolvimento Produtivo das Mulheres Trabalhadoras Rurais e Artesãs Rurais de Santa Cruz da Baixa Verde-PE. The inclusion of these women in the National Program for Strengthening Family Agriculture - Pronaf, was analyzed from the theoretical categories gender relations and sexual division of labor. It is a qualitative research, in which the semi-structured interview was the main instrument

\footnotetext{
1 Graduado em Agronomia (UFRPE). Mestre em Extensão Rural e Desenvolvimento Local (UFRPE). Extensionista Rural do Instituto Agronômico de Pernambuco (IPA). E-mail: agrolucio@hotmail.com.

${ }^{2}$ Graduada em Bacharelado e Licenciatura em História (UFPE). Mestre em História (UFPE). Doutora em História Social (USP). Professora do Programa de Pós-Graduação em Extensão Rural e Desenvolvimento Local (Posmex) da Universidade Federal Rural de Pernambuco (UFRPE). E-mail: ataide@hotlink.com.br.

${ }^{3}$ Graduada em Arquitetura (UFPE). Mestre em Desenvolvimento Urbano (UFPE). Doutora em Estudos Iberoamericanos pela Universidad Complutense de Madrid. Professora do Programa de Pós-Graduação em Extensão Rural e Desenvolvimento Local (Posmex) da Universidade Federal Rural de Pernambuco (UFRPE). E-mail: mrfaleitao@gmail.com.
} 
of data collection. The analysis was based on the theoretical methodological assumptions of Discourse Analysis (AD) elaborated by Foucault and Dijk. The results showed that, in spite of the advances in the access of these women to the credit of Pronaf, it is operationalized, based on the dialogue and the contributions made by the respective partners. In this way, the hierarchy of power is maintained in the process of managing these economic resources, but they have extended cultural, political and decision-making spaces.

Keywords: discourse analysis, Pronaf, rural women.

\section{INTRODUÇÃO}

A década de 1990 constitui-se um marco na construção de políticas públicas relacionadas à agricultura familiar ${ }^{4}$ no Brasil. Anteriormente, a monocultura e o latifúndio monopolizavam os recursos econômicos na perspectiva de valorização especialmente das exportações. Constata-se mudança nesse cenário, quanto às políticas públicas, a partir das mobilizações sociais de grupos vinculados à agricultura familiar, de mudança nos padrões dos estudos rurais e dos interesses do governo federal em conservar a ordem social no campo, além da atuação do movimento sindical rural (GRISA; SCHNEIDER, 2014).

Neste contexto, uma das primeiras políticas públicas direcionadas aos agricultores familiares, como forma de reconhecimento e legitimação da categoria pelo Estado, foi o Programa Nacional de Fortalecimento da Agricultura Familiar (Pronaf) ${ }^{5}$, em 1996, com o objetivo de corroborar a produção da agricultura familiar, por meio da geração de emprego e renda no meio rural, melhorando a qualidade de vida dos agricultores familiares (SCHNEIDER; CAZELLA; MATTEI, 2009).

No ano de 1997, o Pronaf expandiu o crédito para além do custeio, pois incluiu as linhas de investimentos, infraestrutura e serviços municipais, além da capacitação e pesquisa. Nesta data, o programa foi operacionalizado em todo território nacional (SOUZA-ESQUERDO; BERGAMASCO, 2014).

Vale ressaltar que,

O sistema de produção da agricultura familiar combina a posse dos meios de produção e a realização do trabalho. Não há separação entre gestão da propriedade e execução do trabalho, estando ambos sob responsabilidade do produtor $\mathrm{e}$ sua família (LIMA; JUNQUEIRA, 2008, p. 159).

Por essa ótica, mesmo sendo o Pronaf, uma política direcionada para a família, o que teoricamente contemplaria todos os membros, constata-se que o acesso e a gestão dos recursos são realizados, em sua grande maioria, por homens. Partindo da premissa apontada por Spavenello, Matte, Boscardin (2016) de que o poder de decisão nas propriedades é, em sua maioria, exclusividade masculina,

\footnotetext{
${ }^{4}$ A legislação brasileira - Estatuto da Terra, Lei 4.504/64 e a Lei $n^{\circ} 11.326 / 06$ caracteriza a agricultura familiar como sendo aquela desenvolvida em propriedades rurais de até 04 (quatro) módulos fiscais, em que predomina o trabalho familiar sobre a mão-de-obra total do estabelecimento. O valor da unidade "módulo fiscal" é fixado pelo INCRA, e varia de município para município, com base nos critérios do art. $\mathrm{n}^{\circ} 4$ do Decreto 84.685/80 Bianchini (2005 apud JUNQUEIRA; LIMA, 2008, p. 162).

${ }^{5}$ O Programa Nacional de Fortalecimento da Agricultura Familiar (Pronaf) destina-se a estimular a geração de renda e melhorar o uso da mão de obra familiar, por meio do financiamento de atividades e serviços rurais agropecuários e não agropecuários desenvolvidos em estabelecimento rural ou em áreas comunitárias próximas. Disponível em: https://www.bcb.gov.br/pre/bc_atende/port/PRONAF.asp. Acesso em: 12 jan. 2017.
} 
torna-se possível considerar que para as mulheres fica alguma autonomia quando a atividade produtiva não é central na geração de renda da propriedade.

Apenas a partir de 2003 , criou-se uma linha específica para as mulheres: Pronaf Mulher ${ }^{6}$, como uma forma de reduzir a desigualdade de gênero, no que se refere às políticas públicas. Além de possibilitar, segundo Fernandes (2008), autonomia econômica e visibilidade às atividades desenvolvidas pelas mulheres no espaço doméstico e ao seu redor. Ou seja, uma autonomia vinculada diretamente ao exercício da cidadania.

No que se refere ao acesso das mulheres às políticas públicas, especificamente o crédito rural no município de Santa Cruz da Baixa Verde, sertão do Pajeú pernambucano, apenas após a organização, formalização e fundação da Associação Municipal de Desenvolvimento Produtivo das Mulheres Trabalhadoras Rurais e Artesãs Rurais de Santa Cruz da Baixa Verde-PE, é que as mulheres desta localidade acessaram efetivamente o Pronaf, com a finalidade de investir nas atividades agrícolas e não agrícolas. No período de 2008 a 2014, catorze (14) associadas acessaram ao crédito rural, linha Pronaf $\mathrm{B}^{7}$, por meio do programa Agroamigo.

A partir desse contexto, surgem alguns questionamentos: o acesso ao crédito rural por essas mulheres possibilitou alguma alteração dos papéis sociais de gênero? A divisão sexual do trabalho ${ }^{8}$ interferiu de alguma forma no momento de acessar ao crédito? Para responder essas indagações, o artigo tem como objetivo analisar a relação entre gênero e acesso ao crédito rural, enfatizando a divisão sexual do trabalho e os papéis sociais de gênero.

A abordagem da pesquisa é qualitativa, a partir pesquisa exploratória9: acesso ao crédito rural pelas mulheres da Associação Municipal de Desenvolvimento Produtivo das Mulheres Trabalhadoras Rurais e Artesãs Rurais de Santa Cruz da Baixa Verde-PE, tendo como instrumento de coleta de dados a entrevista semiestruturada. Para a análise de dados, foi fundamental a Análise do Discurso (AD) a partir da literatura sobre o tema, especialmente Michel Foucault e Teun A. van Dijk.

O artigo está dividido em cinco partes, além da introdução e das considerações finais: a primeira refere-se ao debate teórico sobre os temas de gênero e crédito rural; na segunda, aborda-se o controle do discurso na perspectiva de Foucault; na seguinte, apresentam-se as estratégias discursivas a partir de Van Dijk; na quarta parte são apresentados os dados com a explicação sobre os procedimentos metodológicos, uma caracterização do município e da associação; na última parte, são analisados os discursos das entrevistadas, obtidos por meio das entrevistas semiestruturadas, a partir da teoria de Foucault e Dijk.

\footnotetext{
${ }^{6}$ Crédito de investimento para atender às necessidades da mulher produtora rural que apresente Declaração de Aptidão ao Pronaf (DAP). É possível financiar investimentos destinados à construção, reforma ou ampliação de benfeitorias e instalações na propriedade rural, aquisição de máquinas, equipamentos e implementos, aquisição de matrizes, formação e recuperação de pastagens, proteção e correção do solo, aquisição de bens como tratores e embarcações, entre outros. Disponível em http://www.bb.com.br/pbb/pagina-inicial/agronegocios/agronegocio---produtos-e-servicos/credito/investir-emsua-atividade/pronaf-mulher\#/. Acesso em: 12 jan. 2017.

${ }^{7}$ Microcrédito rural (Pronaf B): direcionado aos agricultores de mais baixa renda, para o financiamento das atividades agropecuárias e não agropecuárias, podendo os créditos cobrirem qualquer demanda que possa gerar renda para a família atendida.

${ }^{8}$ A análise se apoia no conceito de divisão sexual do trabalho desenvolvido por Kergoat (2003) no qual afirma que a forma de divisão do trabalho social é decorrente das relações sociais de sexo; esta forma é adaptada historicamente e à cada sociedade. Ela tem por características a destinação prioritária dos homens à esfera produtiva e das mulheres à esfera reprodutiva e, simultaneamente, a apreensão pelos homens das funções de forte valor social agregado.

${ }^{9}$ Consiste em um estudo preliminar sobre relações de gênero e crédito.
} 


\section{CONSIDERAÇÕES SOBRE GÊNERO E CRÉDITO RURAL}

A partir do tema, as relações de gênero e o acesso ao crédito, considera-se importante abordar elementos sobre a dimensão de gênero, em que mulheres e homens são socializados diferentemente. Isso faz com que espaços de poder sejam ocupados a partir da concepção de feminilidade e masculinidade.

O conceito de gênero parte de uma necessidade de introduzir a dimensão da relação entre os sexos na perspectiva de que esta relação não é um fato natural, mas construída e remodelada, efeito e motor da dinâmica social; relação que produz saberes e categoria de análise. A referência ao gênero ao invés de sexo aponta para a condição das mulheres, pois não está determinada pela natureza, pela biologia ou pelo sexo, mas pelo resultado de uma invenção social e política. Nesse sentido, uma construção simbólica integrante do regime de emergência dos discursos que configuram sujeitos. Tenta-se desconstruir 0 universal e evidenciar a sua historicidade (COLLING, 2004).

Defensora do conceito de gênero como categoria útil de análise histórica, Joan Scott afirma que gênero é a organização social da diferença sexual, sem refletir a realidade biológica primeira, mas como construção do sentido da realidade. Tal prerrogativa a faz considerar a diferença sexual como uma estrutura social móvel a ser analisada nos seus diferentes contextos históricos (SCOTT, 1998).

Quanto às subjetividades sociais, associa-se o feminino à natureza, emoção, amor, intuição, destinado ao espaço privado. Já o masculino, vincula-se à cultura, política, razão, justiça, poder, público. Tal dicotomia apresenta uma oposição desigual entre homens e mulheres, evidenciando a sujeição destas aos homens dentro de uma ordem aparentemente igualitária e universal. Colling (2004) considera os papéis destinados ao masculino ou ao feminino como produtos na configuração do poder, lugares ocupados em uma situação estratégica complexa, em que o masculino exerce um poder maior que o feminino.

Sorj (2004) afirma que uma das principais convergências da experiência feminina é o padrão de atribuir as responsabilidades domésticas e familiares aos indivíduos do sexo feminino, reforçando o princípio cultural de que as propriedades femininas residem na esfera doméstica e as masculinas nas atividades profissionais (SORJ, 2004). A autora tem desenvolvido pesquisas no âmbito do cuidado e do uso do tempo, em que as mulheres estão inseridas.

Outro elemento importante nas discussões que envolvem gênero é a divisão sexual do trabalho, considerada por Nogueira (2011), um fenômeno histórico e social, já que se transforma e reestrutura-se de acordo com o capital, em que o trabalho doméstico não remunerado é de responsabilidade das mulheres, independente de sua participação no mercado de trabalho.

Kergoat (2003) chama a atenção para alguns princípios organizadores da divisão sexual do trabalho na sociedade: 1) o princípio de separação, que pressupõe a realização de atividades exclusivamente por homens e outras por mulheres; 2) o princípio de hierarquização, no qual os trabalhos são diferentemente valorizados, ficando para as mulheres os relacionados à reprodução social, de menor valor. Tudo isso perpetuado a partir da naturalização fundamentada na divisão biológica das diferenças sexuais. O que segundo a autora "reduz as práticas sociais" a "papéis sociais" sexuados, os quais remetem ao destino natural da espécie.

Por outro lado, a divisão sexual do trabalho tem sido teorizada a partir de outras dimensões, entre elas: 1) são construções sociais, por isso não são provenientes de um determinismo biológico; 2) a vida cotidiana está fundamentada em bases materiais e ideológicas; 3 ) há relações hierárquicas entre os sexos, que 
definem relações de poder, de dominação historicamente construídas nas sociedades (KEGOART, 2003).

Os estudos sobre divisão sexual do trabalho consideram esta hierarquização como um paradigma das relações de dominação. Por isso, constituise em um conceito importante na análise sobre o acesso ao crédito por agricultoras que historicamente se constituem em mulheres que exercem as atividades de produção e reprodução social.

Verifica-se uma desigualdade social bastante acentuada quanto às relações de gênero construídas até hoje, enfatizando a hierarquia em que prevalece o poder exercido pelos homens sobre as mulheres, presente de forma intensa no meio rural.

Inclusive nos Programas Rurais que, geralmente, a consideram uma beneficiária passiva, restrita às atividades domésticas, com exceção nos casos em que exerce a chefia da família (MELO, 2003).

Nesse sentido, Inácio e Leitão (2012) colocam que desde a inclusão da mulher nas relações produtivas ocorreram várias mudanças significantes na organização social familiar durante o século XX. No entanto, ainda se constatam desigualdades de remuneração, acessibilidade e tratamento entre homens e mulheres. Ressalta-se que mesmo com a participação da mulher em determinados espaços públicos, ainda Ihes são atribuídas os papéis específicos na manutenção do lar, independente de sua participação nas atividades produtivas, além de serem alvos de preconceito, violência doméstica e machismo por parte da sociedade. Diante desse contexto, os autores apontam a necessidade e a importância das políticas públicas específicas às mulheres, promovendo a inclusão social.

Quanto a políticas públicas destinadas aos agricultores familiares, a primeira e mais importante no Brasil foi o Programa Nacional de Fortalecimento da Agricultura Familiar (Pronaf), criado em 1996, e que representa o reconhecimento e a legitimação do Estado em relação às especificidades da agricultura familiar como categoria social (SCHNEIDER; CAZELLA; MATTEI, 2009). A partir do Pronaf, medidas de fortalecimento e garantia da produção agrícola da agricultura familiar foram construídas, como a retomada da Assistência Técnica e Extensão Rural (Ater) (GRISA; SCHNEIDER, 2014).

Bianchini (2015) ao analisar os 20 anos do Pronaf apontou a importância desse programa para os agricultores familiares, ressaltando que desde a sua existência, mais de $R \$ 160$ bilhões foram aplicados, de modo a ultrapassar 26 milhões de contratos, em diversas modalidades. Assim, contemplaram-se diferentes tipologias da agricultura familiar como, por exemplo, a linha de investimento do Pronaf Mais Alimentos com o financiamento de mais de 50.000 tratores e o microcrédito (Pronaf B) por meio do Agroamigo (BNB) que financiou mais de 5,6 bilhões de reais para as atividades desenvolvidas pelas famílias abaixo da linha da pobreza no semiárido.

Vale ressaltar que o Pronaf $B$ é o microcrédito rural que tem por finalidade financiar as atividades agropecuárias e não agropecuárias desenvolvidas no estabelecimento rural ou em áreas comunitárias rurais próximas. Além disso, serve para a implantação, ampliação ou modernização de infraestrutura de produção e prestação de serviços agropecuários e não agropecuários, podendo ser financiada qualquer demanda que possa gerar renda para a família atendida. As famílias beneficiárias são aquelas com renda bruta anual de até $R \$ 20$ mil (MDA, 2017).

$\mathrm{Na}$ região Nordeste, destaca-se o Agroamigo, programa de microcrédito rural orientado do BNB que é composto metodologicamente pelas seguintes etapas: abertura de área, mapeamento do mercado, promoção e palestras informativas, entrevista, elaboração da proposta simplificada de crédito, visita prévia, análise da proposta, contratação do crédito, liberação do crédito, visita de verificação, visita de 
orientação, administração da carteira, assistência técnica, acompanhamento grupal e renovação do crédito (MACIEL, 2009).

Entretanto, como apontam Spavanello, Matte, Boscardin (2016), as linhas de crédito não diferenciavam o acesso para homens e mulheres, já que o recurso era direcionado para o conjunto da família. Com o objetivo de possibilitar o acesso ao crédito pelas mulheres, para que pudessem investir na atividade que desejassem, criou-se uma linha de financiamento específica, o Pronaf Mulher, em 2003, tornando-se uma forma de amenizar as diferenças entres mulheres e homens quanto à gestão e ao trabalho das unidades produtivas.

O Pronaf Mulher, através do crédito como estratégia de desenvolvimento rural, apresenta em seu discurso o objetivo de criar situações e "condições para o aumento da capacidade produtiva, a melhoria da qualidade de vida e a aplicação do exercício da cidadania das mulheres, a partir da ampliação de sua autonomia, participação econômica e política, no seu contexto familiar e social" (BRASIL/MDA/NEAD, 2005, p. 14).

Pressupõe-se que, através do acesso ao microcrédito, as mulheres tenham novas oportunidades de adquirir conhecimento, permitindo-lhes ampliar suas opções, tanto na vida pessoal quanto nos espaços públicos (HERNANDÉZ, 2009).

\section{CONTROLE DO DISCURSO NA PERSPECTIVA DE FOUCAULT}

O meio rural brasileiro ainda é marcado por suas raízes históricas dos períodos coloniais, fundamentada na concentração de renda e poder. A produção camponesa tradicional reproduz a hierarquia presente nestas relações de poder. Neste caso, o patriarcal exercido pelos homens em relação às mulheres, seja no espaço privado ou no espaço público, o que reflete diretamente em suas ações e discursos. Dentre as discussões sobre a relação entre discurso e poder, destacamse os estudos realizados por Michel Foucault.

A prática discursiva para Foucault, segundo Cordeiro (1995), é um grupo de princípios "anônimos, históricos, sempre determinados no tempo e no espaço, que definiram, numa dada época, e para uma determinada área social, econômica, geográfica ou linguística, as condições de exercício da função enunciativa". Para Foucault (2014), o discurso não é algo que apenas expressa (ou oculta) o desejo; é aquilo que é o objeto do desejo; ao considerar que o discurso não é apenas aquilo que representa as lutas ou sistemas de dominação, mas a razão pela qual, pelo que se luta, isto é, o poder do qual se quer apoderar.

Ao abordar o discurso enquanto poder, Foucault (2014) aponta para o controle, a seleção e a organização do discurso, o que vincula diretamente ao controle, à coerção e à exclusão social:

[...] suponho que em toda sociedade a produção do discurso é ao mesmo tempo controlada, selecionada, organizada e redistribuída por certo número de procedimentos que têm por função conjurar seus poderes e perigos, dominar seu acontecimento aleatório, esquivar sua pesada e temível materialidade (FOUCAULT, 2014, p. 8).

E dentre os elementos de controle e delimitação do discurso, destacam-se: os relacionados ao modo exterior, com a função de sistemas de exclusão, vinculado à parte do discurso que põe em jogo o poder e o desejo; os procedimentos internos, em que os discursos exercem o seu próprio controle, com a função de classificar, ordenar e distribuir, submetendo-se à dimensão do acontecimento e do acaso; e o 
terceiro grupo de procedimentos que determina as condições de funcionamento do discurso, impõe aos indivíduos que o pronuncia uma quantidade de regras, impedindo que todos tenham acesso a ele (FOUCAULT, 2014).

Os procedimentos citados acima são catalogados por Foucault, segundo Cordeiro (1995), em três sistemas de exclusão do discurso: a) externos ao discurso o interdito, a partilha da razão e da loucura e a vontade de verdade; b) internos ao discurso - o comentário, o autor, as disciplinas teóricas; c) exclusão dos sujeitos falantes - rituais da palavra, sociedades de discurso, doutrinas e apropriações sociais.

Os respectivos procedimentos evidenciados por Foucault serão utilizados na análise das relações de poder construídas entre homens e mulheres, sabendo-se que as subjetividades são constituídas através de diferentes práticas, no estudo de caso em questão: o crédito acessado pelas mulheres da Associação Municipal Mulher Flor do Campo, em Santa Cruz da Baixa Verde-PE.

\section{ESTRATÉGIAS DISCURSIVAS A PARTIR DE TEUN VAN DIJK}

Dentre os teóricos da Análise de Discurso, destaca-se, em nossa análise, Teun A. van Dijk com os Estudos Críticos do Discurso (ECD), a partir da categoria analítica abuso de poder. Ou seja, as formas de dominação resultam em desigualdade e injustiças sociais, o que caracteriza, em sua grande maioria, a relação entre homens e mulheres.

Para Dijk (2015), o discurso é analisado como uma interação situada, uma prática social ou um tipo de comunicação numa situação social, cultural, histórica ou política. Na perspectiva de abordagem crítica, o foco recai sobre os estudos de questões e problemas sociais, da desigualdade social, da dominação e de fenômenos relacionados, e no papel do discurso, do uso linguístico ou da comunicação em tais fenômenos, em particular. Quanto à dominação masculina, os estudos de Trómel - Plótz (1984, apud DIJK, 2015) apontam que a respectiva dominação não ocorre apenas em situações informais, no espaço privado, mas também surgem em contextos públicos, em que boa parte dos moderadores são homens.

Os estudos de Dijk relacionam o discurso e o abuso do poder, considerando este como a violação de normas e valores fundamentais no interesse daqueles que têm o poder e contra os interesses dos outros. Ou seja, considera o abuso do poder como o uso ilegítimo do poder, a violação de direitos sociais e civis das pessoas. Tal abuso de poder favorece a produção da desigualdade social e a sua reprodução na vida cotidiana (DIJK, 2015).

Dijk (2015) aponta que o discurso ideológico dos membros de um grupo (endogrupo) enfatiza de várias maneiras discursivas as características positivas de "Nosso" próprio grupo e seus membros, e as (supostas) características negativas dos "Outros", o grupo de fora, considerado como exogrupo. Percebe-se que uma estratégia geral envolvida na reprodução discursiva (sexista) de dominação, a saber, a polarização endogrupo-exogrupo (exaltação do endogrupo em detrimento do exogrupo), é realizada de várias formas e em muitos níveis de discurso.

Exemplo disso é a análise semântica mais local, no caso das ressalvas, em que se verifica uma parte positiva sobre Nós e uma parte negativa sobre Eles, identificando algumas estratégias discursivas que reproduzem tal posicionamento, como: negações aparentes; uso de termos pejorativos para designar os membros do outgroup e os contrastes entre os termos utilizados para Nós e para Eles. Implicações e suposições; supergeneralização e exagero dos aspectos negativos dos outros; ênfase nos aspectos positivos dos Outros e na boa relação existente 
entre Nós e os Outros; uso de diminutivos para se referir e dirigir-se ao Outro e do verbo "ter" para representar o Outro como posse; empatias aparentes e alusão a temas relativos à ameaça, invasão e contaminação (ZAVALA; ZARIQUIEY, 2008).

Por considerar que nas relações de gênero construídas socialmente, prevalece o abuso de poder da dominação masculina, na dimensão de injustiça e de desigualdade, refletindo nas formas ilegítimas de ação, optou-se por utilizar como um dos referenciais para análise dos discursos produzidos pelas agricultoras familiares que compõe os sujeitos da pesquisa, os estudos de Teun A. van Dijk, por meio dos Estudos Críticos do Discurso.

\section{PROCEDIMENTOS METODOLÓGICOS}

A abordagem utilizada na pesquisa é qualitativa na perspectiva de analisar a interação de certas variáveis, compreender e classificar processos dinâmicos vividos por grupos sociais. Neste caso específico, as mulheres da Associação Municipal de Desenvolvimento Produtivo das Mulheres Trabalhadoras Rurais e Artesãs Rurais de Santa Cruz da Baixa Verde-PE, além de contribuir para o processo de mudança e possibilitar, em um nível de profundidade mais apurado, o entendimento das particularidades do comportamento das respectivas mulheres no que se refere à divisão sexual do trabalho e papéis sociais de gênero (RICHARDSON, 2008).

Trata-se de uma pesquisa exploratória, ao analisar a relação entre gênero e acesso ao crédito rural, a partir da experiência vivenciada pelas agricultoras familiares da Associação Municipal de Desenvolvimento Produtivo das Mulheres Trabalhadoras Rurais e Artesãs Rurais de Santa Cruz da Baixa Verde-PE, no que diz respeito à autonomia e empoderamento do grupo. A pesquisa exploratória proporciona maior contato com o problema, com o objetivo de evidenciá-lo ou elaborar hipóteses, geralmente, a partir de pesquisa bibliográfica e entrevista com pessoas envolvidas com o problema pesquisado. Tais pesquisas classificam-se como: pesquisa bibliográfica e estudo de caso (GIL, 2007).

Os sujeitos da pesquisa são catorze agricultoras familiares, sócias da associação, que acessaram ao crédito rural, linha Pronaf B, por meio do programa Agroamigo, para investimento em atividades agrícolas e não agrícolas. Elas foram assessoradas pela assistência técnica e extensão rural pública, o Instituto Agronômico de Pernambuco (IPA), no período de 2008 a 2014. Os instrumentos utilizados para coleta de dados foram: pesquisa documental, a partir dos relatórios do IPA; entrevistas semiestruturadas realizadas por amostragem, com cinco agricultoras familiares do respectivo grupo, em dezembro de 2016; e observação do contexto discursivo de palavras e expressões durante as entrevistas. Para análise dos dados, utilizou-se a Análise de Discurso a partir da fundamentação teórica de Michel Foucault e Tem A. van Dijk.

\subsection{CARACTERIZAÇÃO DO MUNICÍPIO SANTA CRUZ DA BAIXA VERDE - PE}

O município de Santa Cruz da Baixa Verde está localizado na porção norte do estado de Pernambuco, sertão do Pajeú, a $442 \mathrm{~km}$ da capital. O principal acesso é realizado pelas rodovias BR-232 e PE-365 (Figura 1). Limita-se ao Norte com o Estado da Paraíba, ao Sul com os municípios de Calumbi e Serra Talhada, ao Leste com os municípios de Triunfo e a Oeste com Serra Talhada (BRASIL, 2005). 
Figura 1 - Mapa do estado de Pernambuco com ênfase no município de Santa Cruz da Baixa Verde

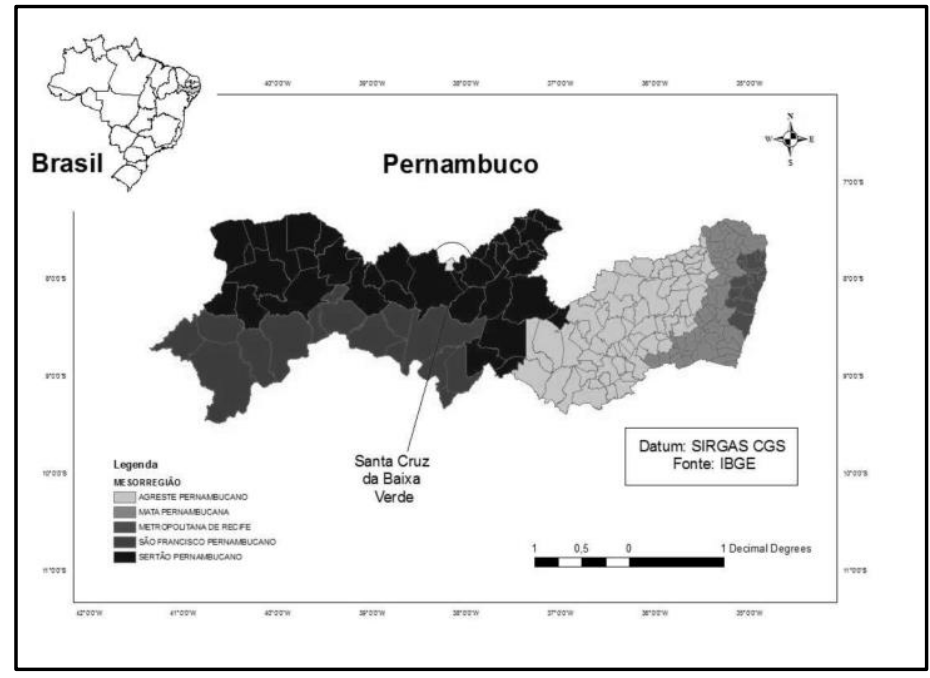

Fonte: Sousa, Lima e Vargas (2014).

Segundo o censo demográfico de 2010, realizado pelo Instituto Brasileiro de Geografia e Estatística (IBGE), o município apresenta uma população total de 11.768 habitantes (5.812 homens e 5.926 mulheres), sendo que 5.277 habitam a área urbana e 6.491 a área rural (3.322 homens e 3.169 mulheres), o que evidencia a inserção de $55 \%$ da população no meio rural. Quanto à distribuição de estabelecimentos rurais, de acordo com o IBGE (2006), 1.329 estabelecimentos familiares ocupam uma área de 6.318 ha, enquanto 138 não familiares ocupam 15.407 ha.

O município é conhecido como a capital da rapadura devido à sua expressiva produção no mercado regional. Além da cana-de-açúcar, destacam-se a produção de milho, feijão, mandioca, banana, goiaba, laranja e café. Salienta-se que boa parte da produção é destinada à subsistência dos produtores rurais do município. Na pecuária, as principais criações são: aves (galinha de capoeira), bovinos, caprinos, ovinos e suínos (IBGE, 2010).

5.2 ASSOCIAÇÃO MUNICIPAL DE DESENVOLVIMENTO PRODUTIVO DAS MULHERES TRABALHADORAS RURAIS E ARTESÃS RURAIS DE SANTA CRUZ DA BAIXA VERDE-PE

A Associação Municipal de Desenvolvimento Produtivo das Mulheres Trabalhadoras Rurais e Artesãs Rurais de Santa Cruz da Baixa Verde-PE é constituída por nove comunidades: Lagoa do Almeida, Serra dos Nogueiras, São Bento, Baixa das Flores, São Paulo, Sítio Santa Cruz, Boa Vista, São Domingos e Bulandeira (Figura 2). 
Figura 2 - Comunidades incluídas na Associação Municipal Mulher Flor do Campo

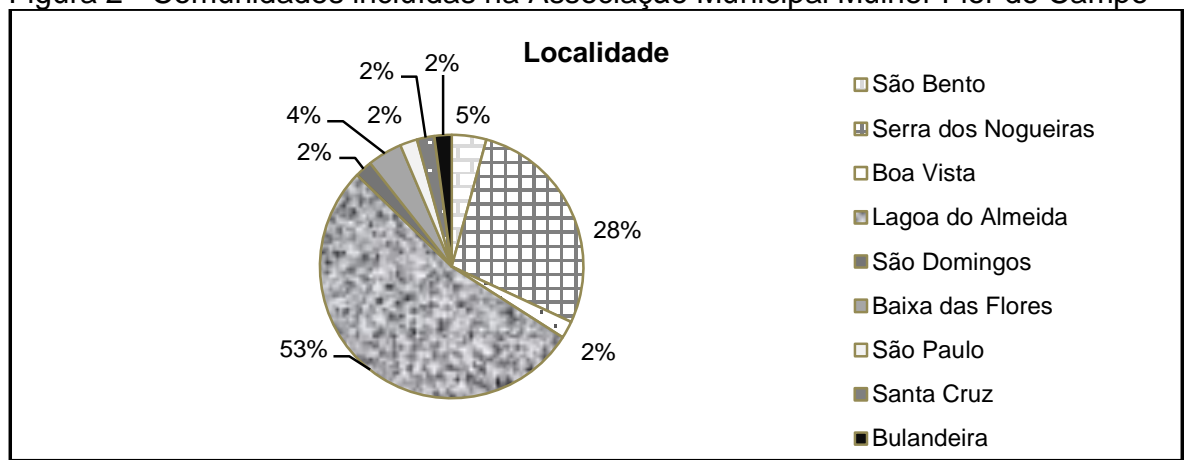

Fonte: Sousa et al. (2016).

Essa associação, fundada em 04 de abril de 2008, agregou na ocasião 43 mulheres que sentiam a falta de um espaço que contemplasse as suas especificidades, diferentemente do que acontecia nas associações consideradas mistas (que tem a participação de homens e mulheres), com o objetivo de fortalecer a organização, produção e comercialização de seus produtos (VIEIRA et al, 2012). Dentro de tal contexto, é possível considerar o grupo heterogêneo, ao se analisar a faixa etária das participantes, conforme mostra Sousa et. al. (2016). Estes ressaltam que $13 \%$ das agricultoras estão abaixo dos 30 anos de idade, aspecto que não se constata com frequência no meio rural (Figura 3):

Figura 3 - Idade das mulheres da Associação Municipal Mulher Flor do Campo

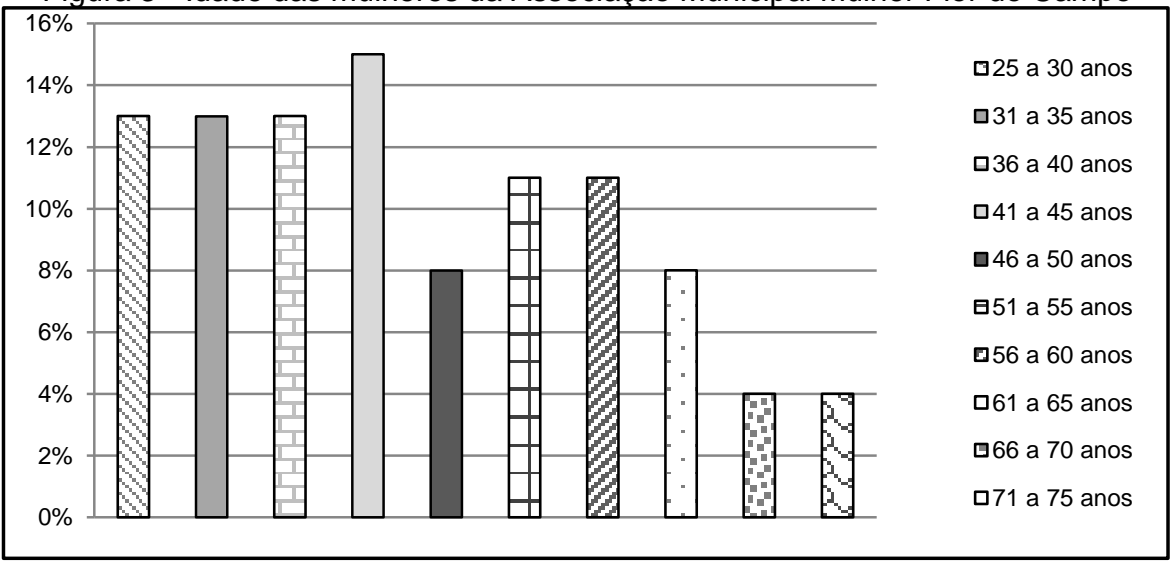

Fonte: Sousa et al. (2016).

As comunidades que compõem a associação estão localizadas no brejo de altitude do município, predominando propriedades que variam de 1,5 a 2,0 ha, em que são cultivadas a cana-de-açúcar (para produção de rapadura), milho e feijão (subsistência) e frutíferas. Na pecuária, destacam-se a criação de aves, ovinos e bovinos, em pequenos rebanhos. A declividade e pedregosidade dos solos na área influencia diretamente a produtividade das culturas agrícolas, refletindo no decréscimo da renda obtida. Uma das alternativas adotadas pelas mulheres, para minimizar esse problema, é a execução da atividade não agrícola. Algo que 
evidencia a produção de artesanato por meio da fibra da bananeira e dos demais materiais encontrados na região (SOUSA, 2016).

\section{ANÁLISE DE DADOS}

Nesta etapa do trabalho, fez-se a análise dos os dados obtidos pelas entrevistas semiestruturadas realizadas com as agricultoras familiares, compostas por quatro blocos: I) IDENTIFICAÇÃO, refere-se aos dados pessoais, familiares e da propriedade; II) CRÉDITO RURAL, constam as informações sobre motivação, atividades, operações, aplicação e gerenciamento sobre o crédito acessado; III) TRABALHO; levanta as questões sobre o trabalho (remunerado e não-remunerado) e sua divisão na família; e IV) PARTICIPAÇÃO, traz a participação da beneficiária em espaços públicos de debate sobre o crédito rural.

As agricultoras entrevistadas estão na faixa etária entre os 29 e 53 anos, apresentando estado civil como casada (60\%) ou união estável (40\%) e todas residem no sítio Lagoa do Almeida, onde também desenvolvem as atividades rurais, sendo que $60 \%$ das mulheres também desenvolvem as atividades rurais no sítio Bulandeira e $20 \%$ também trabalham no sítio Serra dos Nogueira. São áreas consideradas minifúndios, que variam entre 1,0 e 4,1 ha. Quanto à posse da terra, apresentam a seguinte combinação: proprietária e arrendatária (20\%); comodatária $(20 \%)$; proprietária e comodatária $(60 \%)^{10}$.

Identificou-se, no relato das mulheres, que elas acessaram o crédito motivadas pela possibilidade de aumentar a renda e produção, como também melhorar as condições de trabalho e a propriedade, sendo acessado entre duas a cinco vezes por cada a mesma linha de crédito, Pronaf B (Agroamigo). Destaca-se, nesse sentido, o investimento nas seguintes atividades: cultivo da cana-de-açúcar, inhame, pastagem, bovinocultura de leite, artesanato, infraestrutura da propriedade - reforma e construção de cercas e poço (Figura 04). O acesso ao crédito pelas mulheres motivou seus companheiros a aderiram à referida política pública.

Figura 4 - Atividades financiadas

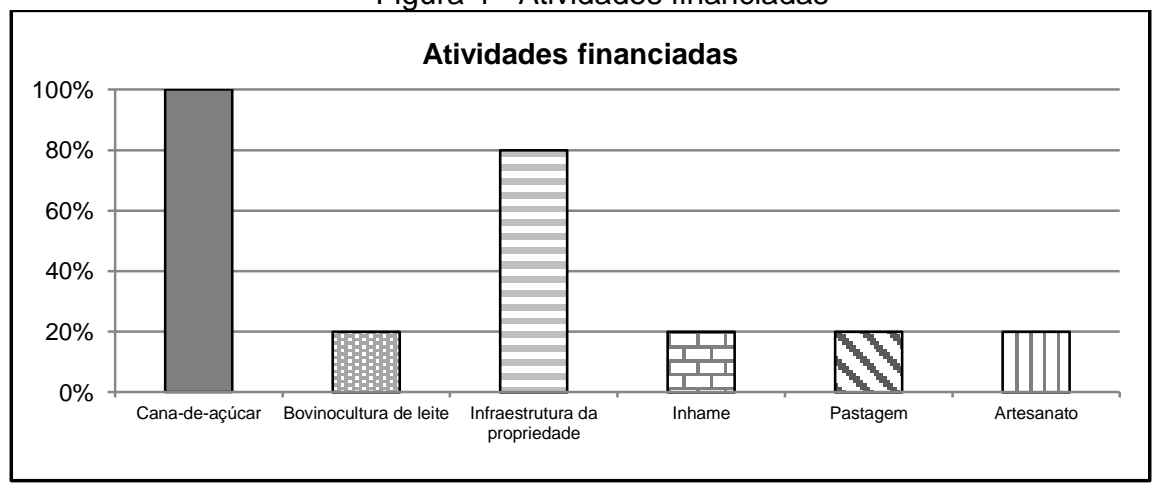

Fonte: Elaborada pelos autores (2017).

\footnotetext{
${ }^{10}$ Proprietária: utiliza a terra com a faculdade de uso e disposição da mesma.

Arrendatária: desenvolve as atividades em terra alugada, por tempo determinado, pagando-se a renda com uma parte da produção.

Comodatária: a propriedade utilizada é por meio de empréstimo gratuito, geralmente entre pais e filhas.

Disponível em: <http://www.sedis.ufrn.br/bibliotecadigital/site/pdf/geografia/Geo_Agra_WEB.pdf > e https://www2.senado.leg.br/bdsf/bitstream/handle/id/506294/codigo_civil_5ed.pdf?sequence=6. Acesso em: 30 jan. 2017.
} 
Durante a gestão dos recursos, foram identificadas quatro situações: a) iniciativa da beneficiária e planejamento e execução pelo casal; b) iniciativa do companheiro e participação na execução e planejamento da beneficiária; c) planejamento do casal e determinação da atividade pela beneficiária; d) a iniciativa do casal e determinação da atividade pelo companheiro (Figura 5). Ressalta-se que os companheiros também acessaram o crédito rural, com exceção de uma família, entre uma a quatro operações.

Figura 5 - Gerenciamento dos recursos obtidos por meio do crédito rural

Gestão dos recursos $\begin{gathered}\text { alniciativa da beneficiária e } \\ \text { planejamento/execução casal } \\ \text { alniciativa do companheiro e } \\ \text { planejamento/execução do casal }\end{gathered}$
$\begin{aligned} & \text { Ilniciativa do casal e } \\ & \text { determinação da atividade pela } \\ & \text { beneficiária } \\ & \text { alniciativa do casal e } \\ & \text { determinação da atividade pelo } \\ & \text { companheiro }\end{aligned}$

Fonte: Elaborada pelos autores (2017).

Constatou-se que mesmo o crédito sendo acessado pela agricultora, apenas em $20 \%$ dos casos a atividade é definida exclusivamente pela mesma, muitas das vezes os seus desejos não são comtemplados, o que aponta para o que Dijk (2015) considera a distribuição desigual do poder na sociedade, nesse caso entre homens e mulheres, fomentado a produção e reprodução da desigualdade social na vida cotidiana.

Quanto à divisão de atividades, constatou-se que as tarefas domésticas cotidianamente são executadas predominantemente pelas mulheres, mas ocasionalmente há colaboração dos homens (60\%), apenas as respectivas atividades são executadas exclusivamente pelas mulheres (20\%), e cotidianamente pelo casal (20\%). As atividades agropecuárias são desenvolvidas pelo casal, destacando-se a criação de galinhas como atividade exclusiva das mulheres (40\%). Ressalta-se a execução das atividades domésticas exclusivamente pelas mulheres nos núcleos familiares em que a agricultora possui faixa etária acima dos 50 anos, refletindo sua formação pautada em valor patriarcal. Dentre as atividades executadas pelas beneficiárias, aponta-se o artesanato (20\%) como representante da categoria não agrícola (Figura 6).

Figura 6 -Atividades desenvolvidas pelos integrantes da família

\begin{tabular}{|ll|}
\hline Atividades domésticas & aMulher \\
aMulher com \\
contribuição do \\
companheiro
\end{tabular}

Fonte: Elaborada pelos autores (2017). 
$\mathrm{Na}$ divisão das atividades que incluem o trabalho doméstico, que é o de reprodução social, não remunerado, geralmente conferido às mulheres, no universo pesquisado, foi possível verificar que apenas $20 \%$ delas realizam todas as tarefas sozinhas. O que significa uma certa ruptura com a hierarquia da divisão social do trabalho apontada na perspectiva foucaultiana como uma manifestação do exercício de poder. Os sujeitos participantes desta pesquisa rompem com o modelo socialmente estabelecido, sobre o qual Colling (2004) afirma que há uma exclusão caracterizada pela separação binária e massiva. Tal separação ocasiona a perda da individualidade a partir do encarceramento da mulher, seja no harém, no convento, na família, no lar. Nesse sentido, é pertinente ressaltar ainda que a separação binária nasce a partir do conceito constituído pelo homem sobre a mulher, presente no discurso, ao considerá-la como diferente, o inacabado, o inferior, e, assim, the confere uma "natureza feminina". Este estigma (GOFFMAN, 1975) acima citado é aquele que as associadas se libertam a partir do empoderamento e parceria realizada nas relações de gênero construídas a partir de uma mobilização para acesso ao crédito, considerando que o financeiro sempre foi historicamente um espaço masculino e uma forma de subordinação das mulheres, conforme depoimento de mulheres trabalhadoras sobre acesso a benefícios sociais ao relatar que os homens desconhecem as necessidades da mulher (LEITÃO; INÁCIO, 2011).

Com o acesso ao crédito, constatou-se mais envolvimento das mulheres nas atividades produtivas, tanto na tomada de decisões, quanto no aumento da participação em trabalho fora da esfera doméstica/reprodutivo por parte das beneficiárias. Isso foi identificado pelas próprias mulheres, ao serem indagadas sobre alguma mudança na divisão sexual do trabalho após o acesso ao crédito. Alguns relatos são significativos sobre o tema, por exemplo, a agricultora $\mathbf{A}$ relata que "teve mais responsabilidade, mais trabalho", assim como a agricultora $\mathbf{E}$, ao constatar que "aumenta o serviço na roça e a preparação da comida dos trabalhadores". Além de uma evolução significativa nas atividades, como apontou a agricultora D: "[...] teve melhora na realização das atividades".

As beneficiárias por meio do crédito rural participaram de reuniões na associação e nas comunidades vizinhas, além do evento regional, Feira da Rapadura, no município, permitindo e ampliando a presença e participação delas em espaços públicos. As agricultoras identificaram como mudanças significativas no seu cotidiano: o aumento da produção e infraestrutura, o trabalho com mais segurança e alternativas, a realização de sonhos, ao investir em atividades como artesanato e bovinocultura de leite (Quadro 1).

Quadro 1 - Percepção sobre mudanças em seu cotidiano após o acesso ao crédito pelas agricultoras familiares

\begin{tabular}{|l|l|}
\hline Agricultora & Depoimento \\
\hline A & $\begin{array}{l}\text { "Melhorou porque a gente já trabalha com mais segurança e mais } \\
\text { possibilidade". }\end{array}$ \\
\hline B & "E uma ajuda. Se não tiver dinheiro não faz o que quer na roça". \\
\hline C & "Melhora, ajudou muito, aumentou quatro vezes o que a gente tinha". \\
\hline D & $\begin{array}{l}\text { "Mudou. Se não fosse o empréstimo não teria como comprar o retalho } \\
\text { para fazer o artesanato, comprar as vacas. Realizar sonhos". }\end{array}$ \\
\hline E & "Ficou melhor". \\
\hline
\end{tabular}

Fonte: Elaborado pelos autores (2017).

Ressalta-se que, durante a realização das entrevistas, nos momentos em que os companheiros estavam presentes, evidenciou-se a cautela nas respostas das 
agricultoras, por meio de olhares e expressões direcionadas aos respectivos cônjuges. No discurso, revelou-se um procedimento de exclusão, identificado por Foucault (2014) como interdição, ou seja: "sabe-se bem que não tem o direito de dizer tudo, que não se pode falar tudo em qualquer circunstância, que qualquer um, enfim, não pode falar de qualquer coisa".

\section{CONSIDERAÇÕES FINAIS}

As mulheres ao acessarem o crédito rural legalmente foram incluídas em um universo socialmente definido para homens. Isto é, o planejamento, a execução e gestão financeira dos recursos obtidos com a operação financeira do Pronaf, em Santa Cruz da Baixa Verde. Na prática, o que foi evidenciado com a realização da pesquisa é que elas expandiram a participação na própria atividade produtiva e em reuniões públicas na associação e nas comunidades vizinhas.

Desta forma, a predominância da iniciativa das agricultoras na adesão à política pública de crédito rural, Pronaf, mesmo que inicialmente não tenha sido a linha de crédito específica para as mulheres foi importante, especialmente, para incentivar seus companheiros a acessarem a respectiva política pública, o que possibilitou um incremento quanto a investimento e rendimento nas atividades agrícolas e não agrícolas desenvolvidas pelas famílias entrevistadas.

Considerando o contexto de naturalização dos papéis de gênero no sertão de Pernambuco, as mulheres entrevistadas apresentaram certa autonomia, o que não implica que houve uma significativa alteração nos papéis sociais de gênero.

Identifica-se nos relatos das entrevistadas a denominação de "ajuda", valor atribuído aos trabalhos domésticos realizados pelos companheiros, o que constitui exemplo de práticas discursivas fundamentadas na "naturalização" de papeis sociais que definem a divisão sexual do trabalho e mantém a hierarquização nas relações de gênero e trabalho.

As associadas que acessaram ao crédito rural já apresentavam um processo de empoderamento, considerando que $30 \%$ do total das agricultoras associadas realizaram esta iniciativa. Dentre estas, estão cinco agricultoras sujeitos desta pesquisa. Neste contexto, verificou-se o aumento da participação destas mulheres em espaços políticos e de discussão no município, como: reuniões sobre políticas públicas na associação, sobre crédito rural nas comunidades vizinhas, presença no espaço do IPA e BNB durante a Feira da Rapadura, de forma ativa, avaliando, contribuindo na construção e consolidação de ações a partir da realidade vivenciada por elas. Esse panorama sinaliza uma alteração nas subjetividades sociais dicotômicas, já que as agricultoras, além do espaço privado, estão presentes e atuando em espaços culturais, políticos e de tomada de decisão.

\section{REFERÊNCIAS}

BIANCHINI, V. Vinte anos do PRONAF, 1995-2015: avanços e desafios. Brasília: SAF/MDA, 2015.

BRASIL. Ministério das Minas e Energia. Diagnóstico do município de Santa Cruz da Baixa Verde. Projeto cadastro de fontes de abastecimento por água subterrânea - estado de Pernambuco. Recife, 2005.

BRASIL. Ministério de Desenvolvimento Agrário (MDA). Núcleo de Estudos Agrários e Desenvolvimento Rural. Cirandas do Pronaf para Mulheres. Brasília, 2005. 
COLLING, A. A construção histórica do feminino e do masculino. In: STREY, M. N.; CABEDA, S. T. L.; PREHN, D. R. Gênero e cultura: questões contemporâneas. Porto Alegre: EDIPUCRS, 2004.

CORDEIRO, E. Foucault e a existência do discurso. Cadernos do Noroeste, v. 8, n. 1, 1995, p. 179-186.

DIJK, T. A. Discurso e poder. São Paulo: Contexto, 2015.

FERNANDES, S. A. Gênero e políticas de crédito: o PRONAF-Mulher em Santa Catarina. Dissertação (Mestrado em Sociologia Política). Universidade Federal de Santa Catarina, Departamento de Sociologia e Ciência Política, Programa de PósGraduação em Sociologia Política, Florianópolis, 2008.

FOUCAULT, M. A ordem do discurso: aula inaugural no Collège de France, pronunciada em 2 de dezembro de 1970. São Paulo: Edições Loyola, 2014.

GIL, A. C. Como elaborar projetos de pesquisa. São Paulo: Atlas, 2007.

GOFFMAN, E. Estigma: notas sobre a manipulação da identidade deteriorada. Tradução: Márcia Bandeira de Mello Leite Nunes. Rio de Janeiro: LTC,1975.

GRISA,C.; SCHNEIDER, S. Três Gerações de Políticas Públicas para a Agricultura Familiar e Formas de Interação entre Sociedade e Estado no Brasil. In: RESR, Piracicaba, v. 52, supl. 1, p. S125-S146, 2014.

HERNANDÉZ, C. O. Política de crédito rural com perspectiva de gênero: um meio de "empoderamento" para as mulheres rurais? Tese (Doutorado em Desenvolvimento Rural). Universidade Federal do Rio Grande do Sul, Faculdade de Ciências Econômicas, Programa de Pós Graduação em Desenvolvimento Rural, Porto Alegre, 2009.

IBGE. INSTITUTO BRASILEIRO DE GEOGRAFIA E ESTATÍSTICA. Censo Agropecuário 2006/Agricultura Familiar: primeiros resultados. 2006.

IBGE. INSTITUTO BRASILEIRO DE GEOGRAFIA E ESTATÍSTICA. Dados do Censo 2010 publicados no Diário Oficial da União do dia 04/11/2010. Dados: Pernambuco. 2010. Disponível em: <http://www.censo2010.ibge.gov.br/dados_divu Igados/index.php?uf=26>. Acesso em: 15 out. 2016.

INÁCIO, P. H. D.; LEITÃO, M. R. F. A. Pesca, gênero e políticas públicas: uma introdução à história da articulação de mulheres pescadoras de Pernambuco. In: LEITÃO, M. R. F. A. ; CRUZ, M. H. S. (Org.). Gênero e trabalho: diversidade de experiências em educação e comunidades tradicionais. Florianópolis: Editora Mulheres, 2012.

JUNQUEIRA, C. P.; LIMA, J. F. Políticas públicas para a agricultura familiar no Brasil. Semina: Ciências Sociais e Humanas, Londrina, v. 29, n. 2, p. 159-176, jul./dez. 2008.

LEITÃO, M. R. F. A.; INÁCIO, P. H. D. O Programa Bolsa Família na voz das pescadoras artesanais do litoral de Pernambuco. Ministério de Desenvolvimento 
Social. Brasília, 2011, p. 64-91. Disponível em: <http://acervodigital.mds.gov.br/xmlui/bitstream/handle/123456789/1056/sumario_11 8.pdf?sequence=1.>. Acesso em: 29 dez. 2017.

KERGOAT, D. Divisão sexual do trabalho e relações sociais de sexo. In: HIRATA, F. L. et al. Dictionnaire critique du féminisme. Tradução: Miriam Nobre. Paris: ed. Presses Universitaires, 2000.

MACIEL, I. S. R. Avaliação da metodologia do Agroamigo em Caucaia - CE. Fortaleza: Banco do Nordeste do Brasil, 2009.

MDA. Ministério de Desenvolvimento Agrário. Microcrédito rural. Disponível em http:<//www.mda.gov.br/sitemda/secretaria/saf-creditorural/microcr\%C3\%A9dito-rural >. Acesso em: 19 jan. 2017.

NOGUEIRA, C. M. O trabalho duplicado: a divisão sexual no trabalho e na reprodução: um estudo das trabalhadoras do telemarketing. São Paulo: Expressão Popular, 2011.

PIRES, M. L. L. S.; SILVA, L. C. Associativismo e políticas públicas nas comunidades rurais: análise da gestão comunitária de saneamento em Pernambuco. In: Revista Políticas Públicas, São Luís, v. 19, n. 2, jul./dez. 2015.

RICHARDSON, R. J. Pesquisa social: métodos e técnicas. São Paulo: Atlas, 2008.

SCHNEIDER, S.; CAZELLA, A.; MATTEI, L. F. Histórico, caracterização e dinâmica recente do Pronaf. In: SCHNEIDER, S.; SILVA, M. K.; MARQUES, P. E. M. (Org.). Políticas Públicas e Participação Social no Brasil Rural. 2. ed. Porto Alegre: Editora da UFRGS, 2009.

SORJ, B. Trabalho remunerado e trabalho não remunerado. In: VENTURI, G.; RECÁMAN, M.; OLIVEIRA, S. A mulher brasileira nos espaços público e privado. São Paulo: Editora Fundação Perseu Abramo, 2004.

SOUZA-ESQUERDO, V. F.; BERGAMASCO, S. M. P. P. Análise Sobre o Acesso aos Programas de Políticas Públicas da Agricultura Familiar nos Municípios do Circuito das Frutas (SP). RESR, Piracicaba-SP, v. 52, Supl. 1, p. S205-S222, 2014 Impressa em Fevereiro de 2015.

SOUSA, G. M. B. et al. A extensão rural e a perspectiva de gênero na agricultura familiar: a atuação do IPA junto à Associação Municipal Mulher Flor do Campo. Extensão Rural, Santa Maria, v. 23, n. 2, abr./jun. 2016, p. 46-59. Disponível em: https://periodicos.ufsm.br/extensaorural/article/view/16985.

SOUSA, G. M. B.; LIMA, F. A. X.; VARGAS, L. P. Assistência técnica e extensão rural: uma análise das estratégias do IPA junto aos agricultores familiares de Santa Cruz da Baixa Verde, PE. In: 52ํㅡㄹ Congresso SOBER, 2014, Goiânia. Anais... Goiânia: SOBER, 2014, p. 1-12.

SPANEVELLO, R. M.; MATTE, A.; BOSCARDIN, M. Crédito rural na perspectiva das mulheres trabalhadoras rurais da agricultura familiar: uma análise do Programa 
Nacional de Fortalecimento da Agricultura Familiar (PRONAF). Polis (Online). Revista Latinoamericana, n. 44, set., 2016, p. 1-18.

VIEIRA, M. N. A. et al. Resgatando a história da Associação Municipal Mulher Flor do Campo. In: II Seminário NEPPAS, 2012, Serra Talhada. Anais... Serra Talhada: UAST/UFRPE, 2012, p. 1-4.

ZAVALA, V.; ZARIQUIEY, R. Peru: "Eu te discrimino porque a falta de educação me ofende". In: DIJK, T.A. (Org.). Racismo e discurso na América Latina. São Paulo: Contexto, 2008. 